\title{
Assessment of Long-Lasting Insecticidal Net Utilization and Its Associated Factors Among Households in Adama District, Oromia Region, Ethiopia
}

\author{
Asnakech Getahun Gebre Mariam ${ }^{1}$, Worku Dugassa Girsha ${ }^{2}$ \\ ${ }^{1}$ Oromia Public Health Research, Capacity Building and Quality Assurance Laboratory Center, Adama, Ethiopia \\ ${ }^{2}$ Department of Public Health, Adama Hospital Medical College, Adama, Ethiopia
}

Email address:

asnakechg@yahoo.com (A. G. G. Mariam),dugassaworku@gmail.com (W. D. Girsha)

To cite this article:

Asnakech Getahun Gebre Mariam, Worku Dugassa Girsha. Assessment of Long-Lasting Insecticidal Net Utilization and Its Associated Factors Among Households in Adama District, Oromia Region, Ethiopia. Science Journal of Public Health. Vol. 4, No. 6, 2016 , pp. 476-481. doi: 10.11648/j.sjph.20160406.20

Received: September 28, 2016; Accepted: October 7, 2016; Published: November 7, 2016

\begin{abstract}
The distribution and use of long-lasting insecticidal net (LLIN) is one of the central interventions for preventing malaria infection. National policy aims to provide one LLIN for every sleeping space (approximately one net per 2 persons in malaria-endemic areas). But still there is inadequate follow-up of its utilization status. This study aimed to assess LLINs utilization and its' associated factors among households in Adama district, Oromia region, Ethiopia. A community-based crosssectional study was conducted. The study subjects were randomly selected 422 households by simple random sampling. Data was collected through interview and observation checklist. Among households who owned LLIN $(96.7 \%)$, only $76 \%$ of household members had slept under LLIN during the previous night prior to interview. Regarding LLINs priority to household family members, only $65.4 \%$ households given priority to their children under five years and $50 \%$ for pregnant women. Concerning to the reasons for not utilizing LLIN, $52.4 \%$ of respondents said that sleeping under LLIN was not convenient and $23.1 \%$ of them were used for other purposes. Those households who are literate (AOR $=2.05,95 \% \mathrm{CI}=1.53-7.09$ ), governmental employees $(\mathrm{AOR}=2.52,95 \% \mathrm{CI}=1.1-6.53)$, roof made up of corrugated iron sheet $(\mathrm{AOR}=1.90,95 \% \mathrm{CI}=1.79$ 4.6) were almost two times more likely to slept under LLIN during the previous night prior to interview. Despite high percentages LLIN ownership, there was still a gap between ownership and use of LLIN. Therefore Public health interventions should also address problems related to utilization status of LLIN.
\end{abstract}

Keywords: LLINs Utilization, Associated Factors, Households, Ethiopia

\section{Introduction}

A cornerstone for malaria disease prevention in Ethiopia is the use of LLINs. The key strategy used by the country is a rolling periodic (every three years) free distribution of LLINs to all pop-ulation groups living in endemic, high and moderate malaria risk areas of Ethiopia. Currently, Ethiopia aims to achieve universal coverage by distributing one LLIN per two persons (sleeping space) through mass, free campaigns at the community level, through the health extenstion workers and/ or health facilities. Ethiopia has distributed about 40 million LLINs since 2005 [1, 2].

By protecting people from being bitten by infected mosquitoes, LLINs are an effective tool to significantly reduce morbidity and mortality due to malaria. Additionally, LLIN has three main functions: i) When mosquitoes are in contact with the net, it has a knock-down effect, temporarily incapacitating or even killing mosquitoes; ii) It has a repellent effect; and, iii) It reduces contact between the person sleeping under the net and mosquitoes by acting as a physical barrier. LLINs also have an effect on other insects, such as head lice, sandflies, ticks and other household pests (e.g. bedbugs and cockroaches) $[3,1]$.

In the absence of proper documentation and follow-up, it may be difficult to ascertain that all LLINs are in the hands of beneficiaries. Therefore, proper follow-up in use of LLINs 
should be one of the elements of the strategic plan concerning lack of adequate knowledge and gaps in information between the provider and client (end user); inadequate surveillance; improper use of LLINs; Use of LLINs only during high transmission season [4, 2].

Key messages for proper and consistent utilization of LLIN are: completely insert the end of the LLIN under the mattress; give priority to pregnant women and children under five to sleep under LLINs; all family members should sleep under LLINs every night; wash your LLIN with regular soap; hang LLINs (or lay to dry) in the shade; do not sell LLIN or use for other purposes $[5,1]$.

About half of the world's population lives in countries at risk of malaria and 97 countries and territories are affected by malaria [6]. Several studies since then reported that, low usage of LLIN in different regions and countries. A study done on awareness, ownership and utilization of Insecticide Treated Nets among Households in a rural community of Southern Nigeria showed that, a total of $75.4 \%$ of those who owned LLIN, only $43.2 \%$ of them used it regularly. Only $33.3 \%$ pregnant women and $37.6 \%$ uder five childer used LLIN [7]. Similarily the survey done in Burkina Faso, the majority of the households $(90 \%)$ owned bed nets and among households possessing at least one LLIN, $70 \%$ of the underfive children had been placed under an LLIN the night preceding the survey [8].

Malaria is ranked as the leading communicable disease in Ethiopia, accounting for about $30 \%$ of the overall disability adjusted life years lost [4]. Approximately 57.3 million $(68 \%)$ of the 84.3 million population of Ethiopia live in areas at risk of malaria. According to the federal ministry of health, malaria was the leading cause of outpatient visits and health facility admissions in 2010, accounting for $14 \%$ of reported outpatient visits and nearly $9 \%$ of admissions. Also Malaria was among the ten leading causes of inpatient deaths among children less than five years of age $[9,1]$.

Apart from coverage, issues regarding the utilization of LLIN are very crucial. This is because the LLIN that are available at a household level may be left unused or even if they are used, vulnerable members of the household may not be given priority and/ or the usage may be intermittent [10, 11]. Increase in LLIN access (i.e. household ownership) does not necessarily translate to equal increase in utilization. Because, the success of LLIN utilization depends on several factors: such as, willingness of people to use nets, inconvenience to hang the nets, educational background, place of residence, age and gender differences, and color of nets $[12,13,14]$.

The study is intended to bridging the information gap, and subsequently to determine the utilization and associated factors of LLIN in Adama district. The findings of the study will help households to improve proper utilization of LLIN. Furthermore, it also helps the region, Adama District and primary health care unit (PHCU) as input to formulate appropriate strategy for program implementation. Therefore, the main purpose of this study was to assess utilization of LLIN and associated factors among household level.

\section{Methods and Materials}

\subsection{Study Design and Setting}

A community-based cross-sectional study was conducted in Adama district, Oromia regional state, central Ethiopia. Adama district is one of the 13 districts in East Shoa Zone. It covers a surface area of 48,556 hectars and has estimated population of 183,502 and 38,230 households in 2015 . The district has four high malaria-endemic kebeles [15]. The study population was all households in four high malaria endemic kebeles of Adama district. The study was conducted from February 1 / 2016 to July 30 / 2016.

\subsection{Sampling Methods}

To select a fairly representative sample of households, the sample size was distributed proportionally to each of the four high malaria endemic kebeles based on the number of households they have. Then household's was randomly selected from a list provided by the district administration by simple random sampling.

\subsection{Sample Size Determination}

The sample size was determined using the single population proportion formula.

$$
\mathrm{n}=\mathrm{Z}^{2} \mathrm{P}(1-\mathrm{P}) / \mathrm{d}^{2}
$$

Where

- $\mathrm{n}=$ Sample size of households.

- $\quad \mathrm{P}=$ Proportion of households slept under LLIN. No previous similar study was carried out in the area and to get maximum sample size $\mathrm{P}$ was taken as $50 \%$ $(\mathrm{P}=0.5)$.

- $\mathrm{d}=$ Degree of accuracy required (sampling error) is $5 \%$ that is, $d=0.05$.

- $\quad \mathrm{Z}=$ Standard score for $95 \%$ confidence level is 1.96 .

- Additional 10\% for non-response rates were taken.

Substituting the above values, the calculated sample size for the study was 422 households.

\subsection{Inclusion and Exclusion Criteria}

Inclusion sampling criteria for this study was being a household living in a registered housing unit from the four high malaria endemic kebeles of Adama district. Those households who were not listed in kebeles profiles were excluded.

\subsection{Ethical Consideration}

The ethical approval and clearance was obtained from Oromia regional health bureau ethical clearance committee. Then at all levels, officials were contacted and permission was secured. All the study participants were informed about the purpose of the study and verbal consent of all study subjects were obtained before data collection. Participants also informed that they have full right to discontinue or refuse to participate in the study. To ensure confidentiality, 
the name of interviewee was not written on the questionnaire. Besides, the interview was made in a place where it was conducive to the study participants in their compound. Each respondent was assured that the information provided by them was confidential and used only for the purpose of research. Moreover, there was no risk or harm that was anticipated from participation of the study.

\subsection{Data Collection Techniques}

Data were collected using semi structured, intervieweradministered questionnaire through house to house and observational check list. Questionnaires were translated in to local language. In order to identify the clarity of questions, pre-testing of the instrument was done. The data collector's were four nurses with ability of speak both Oromifa and Amharic. Two public health officers were engaged in supervision activity. Training was given for both the supervisors and the data collectors for one day before the pretest and for a day after the pretest. The training includes the objectives of the study, method of data collection, checking completeness of questionnaire and the way approaching to the households.

\subsection{Data Processing and Analysis}

After the data were collected and the responses coded, the data was entered into a computer and analyzed using SPSS version 20 . In the analysis process, frequency distribution of variables was worked out in order to describe them. To ascertain the association between dependent and independent variables, adjusted odds ratio with $95 \%$ confidence interval will be calculated at 5\% significance level.

\section{Results}

A total of 422 households participated in this study with a response rate of $100 \%$. Majority of the respondents $(53.5 \%)$ were females. Median age of respondents was 40.7 years. Concerning religion, majority $(60.3 \%)$ were Orthodox Christians and $75.2 \%$ were Oromo in ethinicity. Regarding marital status of the respondents, majority (79.8\%) were married. Almost half of the respondents (49.2\%) were illiterate and $34.9 \%$ were farmers in terms of occupation. Majority $(71.4 \%)$ of the households family size were in the range of less than or equal to five persons. Majority of the house roofs $(90.8 \%)$ were made of corrugated ironsheet and $46.7 \%$ of the respondants had only one bed room. Only $28.1 \%$ of respondents had the average monthly income of 800 Birr and above (table 1).

Table 1. Socio demographic characteristics of the respondents in Adama district, Oromia region, Ethiopia, $2016(N=422)$.

\begin{tabular}{lll}
\hline Characteristics & Frequency & (\%) \\
\hline Sex & & \\
Male & 196 & 46.5 \\
Female & 226 & 53.5 \\
Age & & \\
$18-24$ & 20 & 4.8 \\
\hline
\end{tabular}

\begin{tabular}{|c|c|c|}
\hline Characteristics & Frequency & $(\%)$ \\
\hline $25-44$ & 263 & 62.2 \\
\hline $45-64$ & 110 & 26.0 \\
\hline$>64$ & 29 & 7.0 \\
\hline \multicolumn{3}{|l|}{ Religion } \\
\hline Muslim & 51 & 12.1 \\
\hline Orthodox & 255 & 60.3 \\
\hline Protestant & 111 & 26.2 \\
\hline Other & 6 & 1.4 \\
\hline \multicolumn{3}{|l|}{ Ethnicity } \\
\hline Oromo & 318 & 75.2 \\
\hline Amhara & 52 & 12.4 \\
\hline Gurage & 7 & 1.6 \\
\hline Wolayita & 3 & 0.6 \\
\hline Kembata & 20 & 4.8 \\
\hline Others & 23 & 5.4 \\
\hline \multicolumn{3}{|l|}{ Marital status } \\
\hline Married & 337 & 79.8 \\
\hline Single & 9 & 2.2 \\
\hline Divorced & 22 & 5.2 \\
\hline Widowed & 50 & 11.7 \\
\hline Separated & 4 & 1.0 \\
\hline \multicolumn{3}{|l|}{ Educational status } \\
\hline Illiterate & 208 & 49.2 \\
\hline Literate & 214 & 50.8 \\
\hline \multicolumn{3}{|l|}{ Occupational status } \\
\hline Housewifes & 133 & 31.4 \\
\hline Farmers & 147 & 34.9 \\
\hline Daily labourers & 31 & 7.3 \\
\hline Government employees & 36 & 8.6 \\
\hline Merchants & 29 & 7.0 \\
\hline Other & 46 & 10.8 \\
\hline \multicolumn{3}{|l|}{ Family size of households } \\
\hline$\leq 5$ & 301 & 71.4 \\
\hline$>$ & 121 & 28.6 \\
\hline \multicolumn{3}{|c|}{ Roof house of the household } \\
\hline Grass roof & 40 & 9.2 \\
\hline Corrugated iron shet & 382 & 90.8 \\
\hline \multicolumn{3}{|c|}{ Sleeping rooms per household } \\
\hline 1 sleeping room & 197 & 46.7 \\
\hline 2 sleeping room & 161 & 38.3 \\
\hline 3 sleeping room & 52 & 12.4 \\
\hline 4 and above & 11 & 2.7 \\
\hline \multicolumn{3}{|l|}{ Monthly income } \\
\hline$<100$ birr & 7 & 1.6 \\
\hline 100-299 birr & 87 & 20.6 \\
\hline 300-499 birr & 108 & 25.6 \\
\hline 500-799 birr & 102 & 24.1 \\
\hline 800 birr and above & 119 & 28.1 \\
\hline
\end{tabular}

Among households who owned LLIN (96.7\%), only 76\% of household members had slept under LLIN during the previous night prior to interview while the remaining $24 \%$ did not use their available nets the previous night prior to interview. According to the respondent's perception a group of household's members who had priority to LLIN usage was $65.4 \%$ for children under five years, $50 \%$ for pregnant women, and $32.9 \%$ equally for all households' members. Concerning the major reasons for not sleeping under the net in the previous night, $51.5 \%$ of responadnts said that sleeping under LLIN was not convenient and $22.6 \%$ of them were used for other purposes. Regarding regular and consistence utilization of LLINs, lessthan half (40.9\%) of households used always the year, where as $59.1 \%$ used only during high transmission period. According to the condition of LLINs 
observed, only $8.5 \%$ of LLINs had holes on it (Table 2).

Table 2. LLIN ownership and utilization by households in Adama district, Oromia region, Ethiopia, 2016.

\begin{tabular}{lll}
\hline Characteristics & Frequency & (\%) \\
\hline Ownership of LLIN & 408 & 96.7 \\
Yes & 14 & 3.3 \\
No & & 72.4 \\
Distribution of LLIN per households & 295 & 27.6 \\
Households that have at least one LLIN & 113 & 76.0 \\
Households that have more than one LLIN & & 24.0 \\
Households' members who slept under an LLIN last night & 310 & \\
Yes & 98 & 8.9 \\
No & & 65.4 \\
LLINs priority to household family members & 38 & 50.0 \\
Adults & 276 & 32.9 \\
P5 years of age & 211 & 3.2 \\
Eregnant women & 139 & 40.9 \\
Don't know & 13 & 59.1 \\
Time of LLIN utilization by household members & & \\
Always the year & 167 & 51.5 \\
During high transmission & 241 & 9.5 \\
The major reasons that household members did not sleep under an LLIN the previous night & & 22.6 \\
Sleeping under an LLIN is not Convenient & 50 & 16.4 \\
Sold & 9 & 8.5 \\
Used for other purpose & & \\
No malaria during this time of the Year & & \\
Presence of hole on LLINs & 22 & \\
Yes & 16 & \\
\hline
\end{tabular}

Table 3 below indicated that, the presence of association between associated factors and LLIN utilization was investigated using bivariate and multivariate analysis. The findings revealed that, there was asignificant association between educational status, occupation and material used to build roof of the house with LLINs utilization. Those households who are literate (AOR $=2.05,95 \% \mathrm{CI}=1.53-7.09)$, governmental employees $(\mathrm{AOR}=2.52,95 \% \mathrm{CI}=1.11-6.53)$, roof made up of corrugated iron sheet $(\mathrm{AOR}=1.90,95 \% \mathrm{CI}=1.79-4.60)$ were almost two times more likely to slept under LLIN during the previous night prior to interview.

Table 3. Bivariate and multivariate logistic regression analysis of factors associated with LLIN utilization in Adama district, Oromia region, Ethiopia, 2016.

\begin{tabular}{|c|c|c|}
\hline \multirow{2}{*}{ Characteristics } & \multicolumn{2}{|l|}{ LLIN utilization } \\
\hline & COR $(95 \% \mathrm{CI})$ & $\operatorname{AOR}(95 \% \mathrm{CI})$ \\
\hline \multicolumn{3}{|l|}{ Educational status } \\
\hline Illiterate & 1.00 & 1.00 \\
\hline Literate & $3.01(1.34,10.63)$ & $2.05(1.53,7.09)^{*}$ \\
\hline \multicolumn{3}{|l|}{ Occupation } \\
\hline house wifes & 1.00 & 1.00 \\
\hline Farmers & $4.31(1.87,9.93)$ & $0.48(0.51,4.28)$ \\
\hline Daily laborers & $1.59(0.51,4.89)$ & $0.63(0.15,2.75$ \\
\hline Governmental employees & $3.69(1.19,7.51)$ & $2.52(1.11,6.53)^{*}$ \\
\hline Merchants & $1.07(0.32,3.63)$ & $0.4(0.85,1.89)$ \\
\hline \multicolumn{3}{|c|}{ Material used to build roof of the house } \\
\hline Grass & 1.00 & 1.00 \\
\hline Corrugated Iron shet & $2.11(1.17,3.82)$ & $1.9(1.79,4.60)^{*}$ \\
\hline \multicolumn{3}{|l|}{ Households Family size } \\
\hline$>5$ & 1.00 & 1.00 \\
\hline$\leq 5$ & $0.41(0.25,0.67)$ & $0.69(0.36,1.33)$ \\
\hline \multicolumn{3}{|l|}{ Monthly income } \\
\hline$<100$ birr & 1.00 & 1.00 \\
\hline 100-299 birr & $0.16(0.02,1.33)$ & $0.18(0.02,1.69)$ \\
\hline 300-499 birr & $0.29(0.17,0.52)$ & $0.34(0.18,0.64)$ \\
\hline 500-799 birr & $0.15(0.07,0.29)$ & $0.19(0.08,0.41)$ \\
\hline 800 birr and above & $0.49(0.29,0.83)$ & $0.89(0.47,1.69)$ \\
\hline
\end{tabular}

$\mathrm{AOR}=$ adjusted odds ratio, $\mathrm{CI}=$ confidence interval, $*$ statistically significant at $\mathrm{P}<0,05$. 


\section{Discussions}

The distribution and use of LLIN is one of the central interventions for preventing malaria infection. According to the National Malaria Strategic plan, to protect everyone living in malaria-risk areas, currently, Ethiopia aims to achieve universal coverage $(100 \%)$ by distributing one LLINs for every sleeping space (approximately one net per two persons in malaria- risk areas) with first priority to children under five years and pregnant women [1]. However, the overall utilization of LLIN among the study participants in Adama district was found to be $76.0 \%$ and out of the total users, $65.4 \%$ were given priority to children under five years and $50 \%$ for pregnant women.

The current internationally recognized standard for malaria protection from mosquito bites is the use of LLIN. Net utilization was defined as having slept under a net during the night preceding the study [2]. While all individuals benefit from sleeping under an LLIN, young children and pregnant women are particularly vulnerable to malaria and hence they are an important target for LLIN use $[1,2]$. According to malaria indicator survey report, for households living $<2,000 \mathrm{~m}$ (i.e., in malaria-endemic areas), $54.8 \%$ owned at least one LLIN which was lessthan our findings $(72.4 \%)$. The reasons may be due to the increase in the distribution of LLINs through out the country. In the same report, households that owned at least one net, $64.7 \%$ of children under five years had slept under LLIN and $63.8 \%$ of pregnant women had slept under LLIN the previous night [2]. When compared to this finding, the coverage for children under five years was almost similar, but the coverage for pregnant women was even lessthan the 2011 coverage. The reasons may be not only distributing nets but the system needs proper follow-up of LLINs usage and adequate surveillance.

In Ethiopia, the study done in Arbaminch districts of Ethiopia revealed that LLINs utilization was (73\%) which was almost in agreement with our finding [16]. Similarily LLIN utilization was reported to be $73.3 \%$ in another a study done in Harari, Ethiopia which was also parallel to this study finding [17]. Also the study done among households in Raya Alamata District, Tigray Ethiopia $68.6 \%$ of them were utilized the LLIN [18] which is slightly lessthan this finging. A population-based survey done in southern Ethiopia showed that, from the total households participated in the study $61.1 \%$ had owned at least one LLIN. Among LLIN-owning households, $66.6 \%$ children under the age of five years and $60.0 \%$ pregnant women slept under an LLIN the night before the survey [19], almost similar to our findings.

In different Africa countries research on LLINs utilization was done, like the proportion of households who owned insecticide treated net was nearly in line with the study finding in Burkina Faso where reported as $90 \%$, but the proportion of LLIN utilization among households in Burkina Faso $(70 \%)$ was slightly lessthan in Ethiopia (76.4\%) [7]. On the other hand, LLIN utilization in southern Nigeria (43.2\%) was lessthan this finding [8], this difference in LLIN utilization may be resulted from differences in the health priorities of the countries.

There was asignificant association between educational status, occupation and material used to build roof of the house with LLINs utilization. Those households, who are literate, governmental employe and roof made up of corrugated iron sheet, were almost two times more likely to sleep under LLIN during the previous night prior to interview. The reasons may be those households who are literate and governmenta employee may get more information than others and those housing roof made up of corrugated iron sheet may be not preferable to mosquito indoor resting.

\section{Conclusion and Recommendations}

Despite high percentages LLIN ownership, there was still a gap between ownership and use of LLIN in Adama district, Oromia region of Ethiopia. Therefore to achieve sustained control of malaria, household coverage of nets alone is not sufficient. Public health interventions should also address problems related to utilization status. Based on the findings of this study, we would like to forward the following recommendation:

- District health office shouid encourage and supervise all family members to sleep under LLINs every night

- All concerned body should encourage the households to give priority to pregnant women and children under five years to sleep under LLINs

- Health Extension Workers should provide monitoring of the LLIN utilization by household in order to enhance regular use of LLIN

- Finally, we recommends further study using direct observation at sleeping time to assess proper utilization of LLIN

\section{Acknowledgments}

We would like to thank Adama general hospital and medical college for facilitating all processes and support to finalize this paper. Our heartfelt and deepest thanks go to Adama district health office for their valuable information and support during the research activities.

\section{Limitations of the Study}

The households that were included in the study were from only one district of malaria-endemic area but other malariaendemic areas in Oromia were not incorporated in this study. Research results therefore are limited to this particular district and cannot be generalized to other districts in Oromia region. Since the data was collected during day time, it makes difficult to observe directly about proper utilization of LLIN by household families. 


\section{References}

[1] Federal democratic republic of Ethiopia, ministry of health, national malaria guidelines, Addis Ababa January 2012.

[2] Federal minisry of health, Ethiopia National Malaria Indicator Survey 2011. Addis Ababa: Federal Ministry of Health, 2012.

[3] Hawley WA, Phillips-Howard PA, terKuile FO, Terlouw DJ, Vulule JM, Ombac M, et al. Community wide effect of permethrin-treated bed nets on child mortality and malaria morbidity in western Kenya. Am J Trop Med Hyg. 2003; 68: 121-7.

[4] President's malaria initiative, Ethiopia Malaria Operational Plan, 2013.

[5] Partnership in Roll Back Malaria. Global Strategic Plan. 20052015.

[6] World Health Organization. World Malaria Report. WHO, Geneva, 2013.

[7] SouleymaneDiabaté, Thomas Druetz, Emmanuel Bonnet, Seni Kouanda 4, Haddad VRS, Insecticide-treated nets ownership and utilization among under-five children following the 2010 mass distribution in Burkina Faso.: Malaria Journal, 2014; 13 (10.1186/1475-2875): 353.

[8] Johnson OE, Inyang AC, Etuknwa UI, Ekanem UD, Udo UO, Ubom I, et al. Awareness, Ownership and Utilization of Insecticide Treated Nets among Households in a Rural Community in Southern Nigeria. Sch J App Med Sci. 2015; 3 ((2A)): 608-13.

[9] Derebew A, Alemseged F, Birhanu Z, Sena L, Tegegn A, Zeynudin A, et al.: Effect of training on the use of Long Lasting Insecticide Nets on the burden of malaria among vluerable groups, South West Ethiopia. Malar J: 2010; 9: 121.

[10] Sibhatu Biadgilign, Ayalu Reda. HK, Volume. Determinants of Ownership and Utilization of Insecticide-Treated Bed Nets for Malaria Control in Eastern Ethiopia. Journal of Tropical Medicine. 2012 (235015): 7.
[11] Heggenhougen, H. K., Hackenthal, V. V, Geneva: P. Bed net usage and its acceptance at the local level: The behavior and social aspects of malaria control: an introduction and (TDR), World Health Organization, 2015, 3: 7-106.

[12] Bikila Lencha \& Wakgari Deressa; A Qualitative Study on Insecticide Treated Net Utilization and its barriers among Under-Five Children in Adami Tulu District, Oromia Regional State, Ethiopia: Global Journal of Medical Research: 2015: 15 (5).

[13] Ownership and use of insecticide-treated nets during pregnancy in sub-Saharan Africa: a review Malaria Journal 2013, 12: 268).

[14] Tsegaye Berkessa, D. Oljira and B. Tesfa: Insecticide treated nets use and its determinants among settlers of Southwest Ethiopia, BMC Public Health (2016) 16: 106.

[15] Adama district health office report 2015.

[16] Ayalew Astatkie, Amsalu Feleke, Utilization of insecticide treated nets in Arbaminch Town and the malarious villages of Arbaminch Zuria District, Southern Ethiopia, Ethiop. J. Health Dev. 2009; 24 (1).

[17] Zelalem Teklemariam, \&, Aymere Awoke, Yadeta Dessie, Fitsum Weldegebreal: Ownership and utilization of insecticide-treated nets (LLIN) for malaria control in Harari National Regional State Eastern Ethiopia, Pan African Medical Journal. 2015; 21: 52 doi: 10.11604/pamj.2015.21.52.5380.

[18] Girmay Desta Araya, Hailemariam Lemma Reda, Azeb Gebresilassie Tesema, Utilization of Long Lasting Insecticidal Nets Among Household in Malarious Areas of Raya Alamata District, Tigray, Ethiopia Science Journal of Public Health 2015; 3 (2): 216-221.

[19] Deressa W, Yihdego YY, Kebede Z, Batiso E, Tekalegne A. Individual and household factors associated with the use of LLIN in Southern Ethiopia. Trans R Soc Trop Med Hyg 2014 Oct 108 (10); 616-23. 